\title{
Comparative Thermodynamic Analysis of LNG, LPG, Methanol, Ethanol, Biodiesel, and Hydrogen as Alternative Fuels in HCCI Engines
}

\author{
M. Djermouni and A. Ouadha* \\ Laboratoire des Sciences et Ingénierie Maritimes, Faculté de Génie Mécanique, Université des Sciences et de la \\ Technologie Mohamed Boudiaf d'Oran, Oran El-M'nouar, 31000 Oran, Algérie \\ E-mail: $\underline{\text { ah_ouadha@yahoo.fr }}$
}

Received 25 July 2021, Revised 4 October 2021, Accepted 31 October 2021

\begin{abstract}
Aiming to mitigate the problem of harmful emissions arising from the use of conventional fossil fuels, the performances of alternative fuels, namely LNG, LPG, biodiesel, ethanol, methanol, and hydrogen in an HCCI engine have been analyzed. Thus, a thermodynamic model that considers the gas composition of combustion products and the specific heat temperature dependency of the working fluid has been developed. It allows examining the influence of key engine parameters such as the compressor pressure ratio, ambient temperature, equivalence ratio, engine speed, and the compressor isentropic efficiency on the performance of the HCCI engine. The reliability of the model has been successfully verified against various theoretical and experimental data from the literature. Results showed that LNG performs the best in terms of brake efficiency, exergy efficiency, and placed second in terms of brake specific fuel consumption. With the exception of the latter, although it is associated with a higher energy value, hydrogen produces lower performance compared to the other fuels assessed. For all fuels, the largest exergy destruction rates occur in the HCCI engine. It ranges between 78.4 and $87.8 \%$ of the total exergy destruction rate according to the fuel used. The order of exergy destruction rates within the other components differs from one fuel to the other.
\end{abstract}

\section{Keywords: Alternative fuels; HCCI engines; thermodynamic analysis.}

\section{Introduction}

Although diesel engines are regarded as the best prime mover of ships due to their high thermal efficiency, they produce a large amount of pollutants such as sulfur oxides (SOx) and nitrogen oxides (NOx). In addition, the combustion of diesel oil contributes to global warming through carbon dioxide $\left(\mathrm{CO}_{2}\right)$ emissions. Fortunately, it is possible to reduce these emissions to some extent using multiple reliable strategies. An alternative mode of combustion known as "Homogeneous Charge Compression Ignition (HCCI)" emerges as a strong candidate among these strategies. It is a combustion process that combines characteristics of both spark-ignited engines and diesel engines. The HCCI technology requires fuel and air mixing before they are introduced into the cylinder (like in SI engines) and the mixture spontaneously ignites due to the temperature increase during the compression stroke (like in CI engines). Despite their difficult control of the ignition timing, these engines provide, like-diesel engines, high efficiency with low NOx and PM emissions.

This technology also offers high fuel versatility and can be used as long as it can auto-ignite at a reasonable compression ratio for a large selection of fuels of different octane/cetane numbers. Since the HCCI combustion is completely managed by chemical kinetics, it has little sensitivity to fuel characteristics.

Several studies have been performed on the suitability and merits of HCCI engines fuelled with various fuels. However, only a few researches that have thermodynamically analyzed the whole HCCI engines are available in the literature. For example, Khaliq et al. [1] evaluated the effects of turbocharger pressure ratio, ambient temperature, and compressor adiabatic efficiency on first and second laws efficiencies and the exergy destruction taking part in each component of an HCCI engine operating on wet ethanol. It has been shown that the performances regarding the first and second laws of the engine depended more on the turbocharger pressure ratio rather than the two remaining parameters. They pointed out that most of the destruction of exergy occurred in the HCCI engine $(90.09 \%)$, while about $4.39 \%$ of the total exergy destruction was assigned to the heat transfer and fuel vaporization processes and about $4.08 \%$ of the total destruction of exergy occurred in the catalytic converter. The turbine and the compressor were responsible for about $1.43 \%$ of the destruction of exergy in the whole system. Trivedi and Haleem [2] analyzed the effect of varying the effectiveness of the regenerator on the efficiency of an HCCI engine running on wet ethanol. Results indicated that the first and second law-based efficiencies drop as the regenerator effectiveness increases. It is also reported that the exergy destruction in the combustion process made the HCCI engine dominate compared to the other exergy destruction factors, and the catalytic converter came second. Fatehi et al. [3] carried out an energy and exergy study of isobutanefueled HCCI engine. This study demonstrated that with the increment of the charge temperature at the engine inlet deteriorates the indicated work, maximum pressure, and 
entropy generation, while the temperature reigning in the cylinder, availability loss due to heat transfer through cylinder walls, and total availability is increased. The results showed also that an increase in the engine speed increases the total availability and decreases the heat loss availability. An exergy analysis on the combustion process in HCCI engine running on fuel mixture in different proportions of natural gas/DME employing single-zone model was undertaken by Jafarmadar and Javani [4]. The model incorporates a combustion mechanism considering 83 species with 360 reactions. It was revealed that for the variation of the excess air ratios of DME from 6.5 to 14.7 while keeping constant for natural gas $(=7.1)$, the exergy efficiency enhanced to reach $30.2 \%$, and the irreversibilities are reduced to $15.4 \%$.In its turn, the initial temperature reduces the irreversibility and increases the exergy loss by heat transfer. In a previous study, Djermouni and Ouadha [5] analyzed thermodynamically an HCCI engine, turbocharged and fuelled with natural gas. The findings indicate that thermal and exergetic efficiencies were enhanced under the increment of the equivalence ratio, engine speed, and compressor pressure ratio. However, these efficiencies were found to decrease when increasing the ambient temperature. An energy and exergy study of a hydrogen operated HCCI engine coupled to an organic Rankine cycle has been carried out by Khaliq [6]. It was observed that only $49.4 \%$ of the total exergy input was available as a useful exergy output and about $44.6 \%$ was lost due to irreversible processes in the system components. Mamalis and Assanis [7] presented modeling of a boosted HCCI engine based on the second law analysis. Results showed that the system can achieve up to 10 bars mean effective pressure with a maximum brake efficiency of $39 \%$. A study using the first and second thermodynamic laws was carried out by Li et al. [8] to study the energy and energy mapping of three different regimes of combustion in internal combustion engines. Results have shown that HCCI exhibits the highest quality of energy and energy, and CDC does the worst. Djermouni and Ouadha [9] compared the performance of an HCCI engine running on natural gas fuel to LPG as fuels by varying some operating parameters such as compressor pressure ratio and equivalence ratio. Khaliq et al. [10] carried out a thermodynamic study on an HCCI engine fuelled with hydrogen-enriched wet-ethanol. Results showed that the system's energetic and exergetic efficiencies increased with increasing the hydrogen energy supply in the air-fuel mixture. The system exergy analysis showed the HCCI engine exhibited the highest destruction of exergy, and the rise in the hydrogen fraction augmented the maximum available work. Namar and Jahanian [11] carried out a thermodynamic analysis of a hydrogen-fueled HCCI engine to assess the effects of engine input parameters on its performance. Results have shown that the irreversibility and exergy parameters are primarily affected by the closing pressure of the inlet valve and the equivalence ratio.

The current work aims to present a comprehensible thermodynamic model that depicts the functioning operations of a turbocharged HCCI marine engine. Due to many reasons, such as the exorbitant cost for the procurement of full size marine engine test bed, a model that requires only a few data and translates them into useful parametrical results relying on thermodynamics and proven empirical correlations, is always welcomed. Furthermore, the present study adopts a thermal management strategy to handle the inlet temperature required for a successful combustion in the engine, by using the heat generated by the compressor and a variable displacement pump. Moreover, this study accesses the performances of as many as six fuels fed into an HCCI marine engine.

\section{Thermodynamic Modeling \\ 2.1 Investigated Engine and Assumptions}

An eighteen-cylinder, turbocharged and intercooled HCCI engine is considered in the present study to assess its performance by varying some operating parameters such as the engine compression ratio, the fuel-air equivalence ratio, the engine speed, the turbo-compressor pressure ratio, and the engine inlet temperature. Table 1 summarizes the engine specifications.

Table 1. Main engine specifications.

\begin{tabular}{lr} 
Number of Cylinders & 18 \\
Bore $(B) \times$ Stroke $(S)$, mm & $510 \times 600$ \\
Engine compression ratio $\left(r_{c}\right)$ & 17 \\
Engine speed $(N)$, rpm & 500 \\
Equivalence ratio $(\phi)$ & 0.4 \\
Compressor pressure ratio $\left(r_{p}\right)$ & 5.5 \\
\hline
\end{tabular}

A schematic of the system used for the thermodynamic analysis is illustrated in Figure 1. It consists of an HCCI engine, a turbo-compressor, a mixer, an intercooler, a turbine, and a catalytic converter. The turbo-compressor sucks ambient air at state 1 to compress it in order to reach $T_{2}$ and $p_{2}$. The compressed air is partially cooled by water to attain the required temperature $T_{3}$. The partially cooled air is mixed with the injected liquid fuel in the mixer and ensures its vaporization. The premixed gaseous charge enters the engine to realize compression, combustion, and exhaust processes according to the Otto cycle. Exhaust gases from the engine at state 6 enter into the catalytic converter to eliminate the remained unburned fuel and carbon monoxide, before expanding in the turbine to produce the required power to drive the compressor, while the extra flux is bypassed via the waste-gate of the turbine.

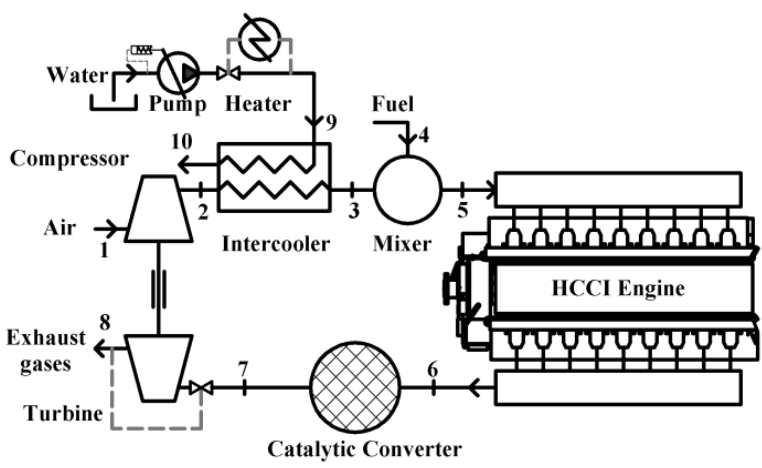

Figure 1. Schematic of the system.

The system thermodynamic modeling and analysis are founded on the following assumptions:

- All processes operate under conditions of steadystate.

- Kinetic and potential rates of energy and exergy are neglected.

- Ambient temperature and pressure are $25^{\circ} \mathrm{C}$ and 101.325 Pa, respectively.

- The combustion is assumed successful for the given conditions (no misfiring). 
2.2 Alternative Fuels Thermodynamic Properties

Due to their non-renewable nature and their harmful pollutant emissions, fossil fuels, mainly petroleum-based fuels, will be less used in the future, and abandonment programs are already developed in many developed countries. This situation has spotlighted the interest in a rapid transition to alternative fuels. In addition to a suitable high volumetric energy density, alternative fuels should meet standards imposed by the IMO regulations.

A large variety of fuels that can be mixed with air before ignition can be used to power HCCI engines. The mixture's combustion is fully controlled by chemical kinetics. Different fuels have different auto-ignition temperatures that can be obtained using appropriate intake temperature and compression ratio. Generally, the fuel auto-ignition temperature decreases with increasing the carbon atoms number [12].

As alternatives, in the present and the near future, liquefied natural gas, LPG, Hydrogen, ethanol, methanol, and biodiesel are considered as serious solutions. However, availability and economic aspects make some of them more realistic solutions than the others. These alternative fuels are explored in the present study. Liquefied natural gas (LNG) as a fuel has been used for the propulsion of LNG carrier vessels for decades, by using the LNG boil-off gas to run steam turbines. Due to its higher hydrogen-carbon ratio compared to conventional marine fuels, natural gas burning results in lower $\mathrm{CO}_{2}$ emissions. Furthermore, NOx emissions are significantly lowered. The utilization of LNG as fuel does not produce SOx as it does not contain sulfur. It also eliminates completely PM emissions. Liquefied Petroleum Gas (LPG) is a well-established fuel mainly used as a cleaner substitute for gasoline for automobiles. It is a blend of propane and butane with different proportions. Hydrogen is a zero-emission fuel that can be extracted from other compounds using electrolysis and steam-methane reforming techniques. However, currently, hydrogen fuel costs are higher than conventional fuels. Ethanol (ethyl alcohol) is an alternative fuel commonly derived from corn and sugarcane. It has been developed a few decades ago mainly to replace gasoline. In addition to the reduction of emissions, the engine can run under higher compression ratios thanks to the higher octane rating of ethanol allowing higher efficiency. As an alternative fuel, it is usually used as a mixture of ethanol and gasoline. It can be also used to $100 \%$ ethanol. Methanol (methyl alcohol) is an alternative fuel that can be extracted from natural gas or biomass. It can be also synthesized from carbon dioxide and hydrogen. As in the case of ethanol, it has been mainly developed to replace gasoline. Due to its high octane rating, methanol as fuel can offer higher thermal efficiencies. Biodiesel is an alternative fuel with similar physical properties to diesel fuel. It can be derived from renewable sources such as animal fats and vegetable oils. Biodiesel, ethanol, and methanol are eco-friendly, non-toxic, bio-degradable, and oxygenated fuels. The above mentioned alternative fuels have different physicochemical properties. Thanks to their simple molecule structures (with the exception of biodiesel), the combustion of these fuels produces much lower pollutant emissions compared to traditional fuels. More particularly, emissions of Particulates and Hydrocarbons are considerably reduced using these fuels. Properties of diesel fuel and alternative fuels considered in this study are summarized in Table 2.

Table 2. Properties of diesel fuel and alternative fuels.

\begin{tabular}{lcccccc}
\hline Properties & Methanol & Ethanol & LNG & LPG & Biodiesel & Hydrogen \\
\hline Density $\left(\mathrm{kg} \mathrm{m}^{-3}\right.$ ) & 798 & 794 & 450 & $510-580$ & $880-920$ & 0.0838 \\
Auto-ignition temperature (K) & 743 & 635 & 810 & $727.6-783.15$ & 422 & 858 \\
Flammability limits (vol. \% air) & $6-36$ & $3-19$ & $4-16$ & $2.2-9.5$ & - & $4-75$ \\
Stoic. air-fuel ratio on mass basis & 6.5 & 9.1 & 17.2 & 15.49 & 12.55 & 34.3 \\
Net heating value (MJ/kg) & 20.1 & 27.0 & $46-50.2$ & 46.3 & 37.4 & 119.9 \\
Flame temperature (K at 100 kPa) & 2163 & 2193 & 2233 & 2243.15 & 2287 & 2318 \\
Octane number & 109 & 109 & 120 & 112 & - & 130 \\
Cetane number & -5 & 8 & -10 & - & $49-58$ & - \\
Kinematic viscosity $\left(\mathrm{mm}^{2} / \mathrm{s}\right)$ & $0.7-1.5$ & 1.1 & $0.14-0.29$ & $1.55-2.8$ & $4-6$ & 110 \\
Heat of evaporation $(\mathrm{kJ} / \mathrm{kg})$ & 1147 & 873 & 479 & 428 & 200 & - \\
Molar Mass $(\mathrm{kg} / \mathrm{kmol})$ & 32.04 & 46.07 & 18 & 51 & 296.5 & 2.015 \\
\hline
\end{tabular}

A careful analysis of the system should take into account the real composition of the working fluid in each state. According to the process under consideration, the working fluid may be considered as air, fuel, fuel-air mixture, or a mixture of burned gases. Furthermore, due to the large temperature variations, a temperature-dependent specific heat capacity at constant pressure, $c_{p}$, is considered to improve the accuracy of the thermodynamic model.

The working fluid is assumed to be a perfect gas. Thus its specific heat capacity at constant pressure is dependent on temperature only. Literature data for temperatures ranging between 298 and $6000 \mathrm{~K}$ have been correlated to the following power-law form:

$c_{p, i}=\sum_{i=0}^{n} a_{i} T^{i}$

where $a_{i}$ are constants determined by regression analysis using literature data for each species.
The expressions of enthalpy, internal energy and entropy are derived from Eq. (1), using

$$
\left\{\begin{array}{l}
h_{i}(T)=h_{00, i}+\int c_{p, i}(T) d T \\
u_{i}(T)=h_{i}(T)-R T \\
s_{i}(T, p)=s_{00, i}+\int \frac{c_{p, i}(T)}{T} d T-R \ln (p) \\
s_{\text {reac }, i}\left(T, p, y_{i}\right)=\int \frac{c_{p, i}(T)}{T} d T-R \ln \left(\frac{y_{i} p}{p_{0}}\right)
\end{array}\right.
$$

where $h_{00, i}$ and $s_{00, i}$ are the integration constants calculated according to an arbitrary reference state. For each gas, the enthalpy constant of integration is the sum of two parts: a part calculated by adjusting $h=0$ at $25^{\circ} \mathrm{C}$ and a part representing the gas enthalpy of formation. For entropy, the integration constant is calculated by adjusting $s=0$ at $25^{\circ} \mathrm{C}$ and $101.325 \mathrm{kPa}$. Note that the reactive mixture specific entropy is not only dependent on the temperature and 
pressure, but also on the molar fraction of the component in the mixture $y_{i}$.

Thermodynamic properties of the combustion products mixture are calculated as the summation of the properties of individual products:

$$
\left\{\begin{array}{l}
c_{p, m}(T)=\sum_{k=1}^{n} x_{k} c_{p, k}(T) \\
h_{m}(T)=\sum_{k=1}^{n} x_{k} h_{k}(T) \\
u_{m}(T)=\sum_{k=1}^{n} x_{k} u_{k}(T) \\
s_{m}(T)=\sum_{k=1}^{n} x_{k} s_{k}(T, p) \\
s_{m, \text { reac }}(T)=\sum_{k=1}^{n} x_{k} s_{k}\left(T, p, y_{i}\right)
\end{array}\right.
$$

where the subscript $k$ denotes the single species and $x_{k}$ is its mass fraction.

\subsection{Thermodynamic Analysis}

Conventionally, the performances of marine engines have been widely assessed using the first law of thermodynamics. This approach takes into account only the quantity of energy and allows the calculation of the thermal efficiency, power, and heat release. However, in addition to the quantity of energy, energy quality is an important indicator of energy utilization. Unfortunately, the energy quality cannot be obtained using only the first law of thermodynamics. Accordingly, the second law of thermodynamics, through the concept of exergy, can achieve this task by providing detailed information on the thermodynamic processes during an engine cycle. In particular, it permits quantifying the exergy destructions in each component of the system and the overall system exergy efficiency.

The balance equations for mass, energy, and exergy are given as

$$
\left\{\begin{array}{l}
\sum_{\dot{m}_{\text {in }}}=\sum \dot{m}_{\text {out }} \\
\dot{Q}-W=\sum \dot{m}_{\text {out }} h_{\text {out }}-\sum \dot{m}_{\text {in }} h_{\text {in }} \\
\sum_{j} \dot{E} x_{Q, j}-\sum_{i} \dot{W}_{i}+\sum_{\text {in }} \dot{E} x-\sum_{\text {out }} \dot{E x}=\dot{E} x_{D}
\end{array}\right.
$$

Within the balance equation of exergy, the first term denotes for the exergy related to a heat transfer, which is given by:

$$
\dot{E} x_{Q}=\left(1-\frac{T_{0}}{T}\right) \dot{Q}
$$

where $\dot{Q}$ is the rate of heat transfer across a boundary in $\mathrm{kW}, \dot{W}$ is the mechanical power rate in $\mathrm{kW}, T$ is the instantaneous temperature across the boundary in $\mathrm{K}$ and $T_{0}$ is the reference state temperature in $\mathrm{K}$.

The second term relates to exergy transfer accompanying the work interaction. The third and the fourth terms correspond to the exergy transfer accompanying mass crossing the boundaries at the inlet and outlet of the control volume, respectively. A stream exergy rate, $\dot{E} x$, is the sum of thermomechanical and chemical exergy rates, i.e.

$$
\dot{E x}=\dot{E} x^{t h}+\dot{E} x^{c h}=\dot{m}\left[\left(h-h_{0}\right)-T_{0}\left(s-s_{0}\right)\right]+\dot{E x} x^{c h}
$$

where $\dot{E} x^{\text {th }}$ is thermomechanical exergy flow rate, $h$ and $s$ signify the specific enthalpy and entropy of the working fluid, respectively, whereas the subscript $O$ denotes the dead state which is generally specified by a temperature of $298.15 \mathrm{~K}$ and a pressure of $101.325 \mathrm{kPa}$.

The rate of chemical exergy of a gas mixture, $\dot{E} x^{c h}$, is calculated using the following expression:

$$
\dot{E} x^{c h}=\left(\dot{m}_{a}+\dot{m}_{f}\right) \bar{R} T_{0} \sum_{i=1}^{k} y_{i} \ln \left(\frac{y_{i}}{y_{i}^{0}}\right)
$$

where $y_{i}$ is the ith constituent molar fraction in the exhaust gas and $y_{i}^{0}$ is the ith constituent molar fraction in the reference environment. The latter is considered a mixture of ideal gases with the following composition on a molar basis: $\mathrm{N}_{2}, 75.67 \% ; \mathrm{O}_{2}, 20.35 \% ; \mathrm{CO}_{2}, 0.03 \% ; \mathrm{H}_{2} \mathrm{O}, 3.12 \%$ and other, $0.83 \% . \bar{R}$ is the universal gas constant and $T_{0}$ is the environment temperature.

The term on the right hand side of Equation (4) represents the total exergy destruction rate in the control volume. It is correlated to the entropy generation by the Gouy-Stodola equation:

$\dot{E} x_{D}=T_{0} \dot{S}_{g e n}$

where, $\dot{S}_{g e n}$ is the rate of entropy generation during the process.

In the following sections, the exergy balance equation is applied to the engine subsystems, namely the turbocharger compressor, the intercooler, the mixer, the engine, the turbine and the catalytic converter.

\subsubsection{Turbocharger Compressor}

The compressor is required to provide a compressed air supply for the engine to improve the power and efficiency. The compressor inlet state (1) is defined by its temperature $T_{1}$ and its pressure $p_{1}$. For a given pressure ratio, $r_{p}=p_{2} / p_{1}$, the compressor outlet properties (state 2) are calculated in two steps. First, the temperature at the final state of the isentropic compression is determined numerically by satisfying the following condition:

$s_{2 s}=s_{1}$

Then, properties at state 2 are calculated by a numerical inversion method and considering the compressor isentropic efficiency defined as

$\eta_{i s, C}=\frac{w_{i s}}{w_{a c}}=\frac{h_{2 i s}-h_{1}}{h_{2}-h_{1}}$

Applying energy and exergy balance on the compressor yields

$$
\begin{aligned}
\dot{E} x_{D, c o m p} & =\dot{E} x_{1}-\dot{E} x_{2}+\dot{W}_{c o m p} \\
& =\dot{E} x_{1}-\dot{E} x_{2}+\dot{m}_{a}\left(h_{2}-h_{1}\right)
\end{aligned}
$$

\subsubsection{Intercooler}

The air compression in the turbocharger is always accompanied by an inevitable increase in temperature. The latter has a negative effect on the density of air. Therefore, cooling is necessary to keep density in a suitable operating range. Furthermore, in HCCI engines, the intercooler plays a role as a combustion controller by altering the charge temperature entering the engine (thermal management).

Cooling water goes into the heat exchanger at a known temperature $T_{9}$ and leaves it at $T_{10}$ taking off some of the heat from the air charge. Thus, the latter is cooled to a 
temperature $T_{3}$, which can be calculated once its enthalpy is determined using the definition of thermal effectiveness:

$$
\dot{H}_{3}=\varepsilon \dot{H}_{9}+\dot{H}_{2}(1-\varepsilon)
$$

where $\varepsilon$ is the intercooler effectiveness.

The exergy destruction rate in the intercooler is given by

$$
\dot{E} x_{D, \text { int }}=\left(\dot{E} x_{2}-\dot{E} x_{3}\right)-\left(\dot{E} x_{10}-\dot{E} x_{9}\right)
$$

\subsubsection{Mixer}

The fuel is injected using the timed injection method. This device is represented herein by a mixer with two inlets for air and fuel and one outlet for the homogeneous charge. The temperature at state 5 could be obtained by a numerical inversion method based on the energy balance of the mixing process:

$$
\dot{H}_{5}=\dot{H}_{3}+\left(\dot{H}_{4}-\dot{H}_{V}\right)
$$

where $\dot{H}_{V}$ denotes the latent heat of vaporization of the fuel. The exergy destruction rate in the mixer may be written as

$\dot{E} x_{D, \text { mix }}=\dot{E} x_{3}+\dot{E} x_{4}-\dot{E} x_{5}$

\subsubsection{HCCI Engine}

HCCI engines operation can be treated using the Otto cycle as depicted in Figure 2. The actual air mass flow rate delivered to the engine is given by

$$
\dot{m}_{a}=\frac{\eta_{v o l} \rho V_{d} N}{2 \times 60}=\frac{\eta_{v o l}\left(p_{5} / R \cdot T_{5}\right) V_{d} N}{2 \times 60}
$$

where $N$ is the engine speed and $\eta_{v o l}$ is the volumetric efficiency calculated based on the compression ratio and the engine inlet temperature by the following expression [13]:

$$
\eta_{v o l}=\frac{r_{c}}{r_{c}-1} \frac{T_{5}}{313+(5 / 6)\left(T_{5}-273.15\right)}
$$

During its introduction in the engine, the temperature of the premixed charge prepared in the mixer is increased by the fraction of residual gases left from the previous cycle according to the following equation [14]:

$$
T_{1}=T_{5}\left[\frac{(1-f)}{1-1 / \gamma r_{c}\left(p_{e} / p_{i}+\gamma-1\right)}\right]
$$

where $f$ is the residual gas fraction, $p_{e} / p_{i}$ is the ratio between exhaust and inlet pressures.

During the compression process $\left(1^{\prime}-2^{\prime}\right)$, the air introduced is heated up to ignition and combustion. For a given compression ratio, properties at state $2^{\prime}$ can be calculated similarly to state 2 using compression isentropic efficiency. The power consumed for the compression of the air-fuel mixture is given by

$\dot{W}_{1^{\prime}-2^{\prime}}=\left(\dot{m}_{a}+\dot{m}_{f}\right)\left(u_{2^{\prime}}-u_{1^{\prime}}\right)$

The exergy destruction rate is calculated using

$$
\dot{E} x_{D, 1^{\prime}-2^{\prime}}=T_{0}\left(\dot{S}_{g e n, 1^{\prime}-2^{\prime}}+\dot{Q}_{l, 1^{\prime}-2^{\prime}} / T_{0}\right)
$$

where $\dot{S}_{g e n, 1^{\prime}-2^{\prime}}$ and $\dot{Q}_{l, 1^{\prime}-2^{\prime}}$ are the entropy generation and heat loss rates throughout the compression process $\left(1^{\prime}-2^{\prime}\right)$, respectively.

HCCI engines are characterized by very fast combustion with a rapid rise in pressure and it can be modeled as constant volume heat gain process $\left(2^{\prime}-3^{\prime}\right)$.

For the combustion reaction, it is assumed that air contains $21 \%$ of oxygen and $79 \%$ of nitrogen. Furthermore, it is supposed that the nitrogen in the air cannot undergo chemical reactions to produce $\mathrm{NO}$ and $\mathrm{NO}_{2}$. Under these statements, the general form of the reaction of one $\mathrm{kmol}$ of fuel $\left(C_{x} H_{y} O_{z}\right)$ with air is written as

$$
\begin{aligned}
& \mathrm{C}_{x} \mathrm{H}_{y} \mathrm{O}_{z}+\frac{1}{\phi}(x+y / 4-z / 2)\left(\mathrm{O}_{2}+3.76 N_{2}\right) \rightarrow \\
& n_{1} \mathrm{CO}_{2}+n_{2} \mathrm{H}_{2} \mathrm{O}+n_{3} \mathrm{~N}_{2}+n_{4} \mathrm{O}_{2}+n_{5} \mathrm{H}_{2}+n_{6} \mathrm{CO}
\end{aligned}
$$

Products mixture composition can be determined assuming the equilibrium criteria by employing the Newton method to solve a set of nonlinear equations. In addition, heat loss resulting from heat flow across the cylinder wall can be determined using

$$
\dot{Q}_{l, 2^{\prime}-3^{\prime}}=h_{c} A\left(T_{3^{\prime}}-T_{w}\right)
$$

Where $A$ is the heat transfer area and $T_{w}$ is cylinder wall temperature.

The convection heat transfer coefficient, $h_{c}$, is calculated using a modified Woschni correlation for HCCI engines [15]:

$h_{c}=3.26 L^{-0.2} p_{\text {avg }}{ }^{0.8} T_{\text {avg }}^{-0.73} \omega^{0.8}$

where $L$ stands for the engine stroke, $\omega$ the mean gases velocity and $p_{\text {avg }}$ and $T_{\text {avg }}$ are the gases average pressure and temperature.

The temperature, $T_{3^{\prime}}$, at the final state of the combustion processes is obtained by an iterative method under the following condition:

$\dot{m}_{f} \eta_{\text {comb }} L H V-\dot{Q}_{l, 2^{\prime}-3^{\prime}}=\left(\dot{m}_{a}+\dot{m}_{f}\right)\left(u_{3^{\prime}}-u_{2^{\prime}}\right)$

where $\eta_{\text {comb }}$ is the combustion efficiency and $L H V$ the fuel lower heating value.

The exergydestruction rate throughout the combustion is calculated using

$\dot{E} x_{D, 2^{\prime}-3^{\prime}}=T_{0}\left(\dot{S}_{g e n, 2^{\prime}-3^{\prime}}+\dot{Q}_{2^{\prime}-3^{\prime}} / T_{\text {comb }}\right)$

where $T_{c o m b}, \dot{S}_{g e n, 2^{\prime}-3^{\prime}}$ and $\dot{Q}_{2^{\prime}-3^{\prime}}$ are the mean gases temperature, entropy generation rate, and heat rate during the compression process $\left(2^{\prime}-3^{\prime}\right)$, respectively.

The working fluid parameters at the final state of the expansion process $\left(3^{\prime}-4^{\prime}\right)$ are also calculated similarly to the compression process $\left(1^{\prime}-2^{\prime}\right)$.

The power produced during the expansion $\left(3^{\prime}-4^{\prime}\right)$ is given by

$\dot{W}_{3^{\prime}-4^{\prime}}=\left(\dot{m}_{a}+\dot{m}_{f}\right)\left(h_{3^{\prime}}-h_{4^{\prime}}\right)$

The exergy destruction rate throughout the expansion process is calculated using

$\dot{E} x_{D, 3^{\prime}-4^{\prime}}=T_{0}\left(\dot{S}_{g e n, 3^{\prime}-4^{\prime}}+\dot{Q}_{l, 3^{\prime}-4^{\prime}} / T_{0}\right)$

where $\dot{S}_{g e n, 3^{\prime}-4^{\prime}}$ and $\dot{Q}_{l, 3^{\prime}-4^{\prime}}$ are the entropy generation rate and heat loss rate during the expansion process $\left(3^{\prime}-4^{\prime}\right)$, respectively.

The temperature $T_{5^{\prime}}$ is calculated by assuming the blowdown process $\left(4^{\prime}-5^{\prime}\right)$ as an adiabatic expansion process.

The exergy destruction during the blowdown process is calculated using

$\dot{E} x_{D, 4^{\prime}-5^{\prime}}=T_{0}\left(\dot{S}_{g e n, 4^{\prime}-5^{\prime}}+\dot{Q}_{l, 4^{\prime}-5^{\prime}} / T_{0}\right)$

where $\dot{S}_{g e n, 4^{\prime}-5^{\prime}}$ and $\dot{Q}_{l, 4^{\prime}-5^{\prime}}$ are the entropy generation and heat loss rates during the blowdown process $\left(4^{\prime}-5^{\prime}\right)$, respectively. 


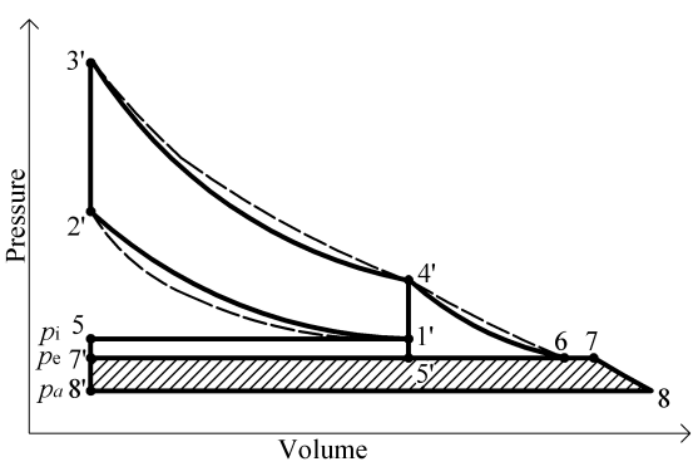

Figure 2. Working cycle in a " $p$-v" diagram

The indicated power produced by the engine is the difference between expansion and compression powers, while the indicated efficiency is defined by the ratio of engine power and the heat added during combustion:

$\dot{W}_{i}=\dot{W}_{3^{\prime}-4^{\prime}}-\dot{W}_{1^{\prime}-2^{\prime}}$

$\eta_{i}=\frac{\dot{W}_{i}}{\dot{m}_{f} \eta_{c o m b} L H V}$

The brake mean effective pressure, bmep, can be determined by:

bmep $=$ imep - fmep $=\frac{\dot{W}_{i} \times 2 \times 60}{N}-$ fmep

The friction mean effective pressure, femp, sum of pumping, mechanical rubbing, and auxiliary mean effective pressures can be calculated using the following expression [16]:

fmep $=\frac{r_{c}-4}{14.5}+0.475 \times 10^{-3} N+3.95 \times 10^{-3} \bar{S}_{p}{ }^{2}$

where, $\bar{S}_{p}$ is the mean piston speed.

The engine brake power is then determined using

$\dot{W}_{b}=\frac{\text { bmep } \times V_{d} \times N}{2 \times 60}$

The engine brake efficiency is expressed as

$\eta_{t h}=\frac{\dot{W}_{b}}{\dot{m}_{f} \eta_{\text {comb }} L H V}$

The exergy destruction occurring in the engine is the sum of exergy destruction rates resulting from compression, combustion, expansion, and blowdown processes:

$\dot{E} x_{D, H C C l}=\dot{E} x_{D, 1^{\prime}-2^{\prime}}+\dot{E} x_{D, 2^{\prime}-3^{\prime}}+\dot{E} x_{D, 3^{\prime}-4^{\prime}}+\dot{E} x_{D, 4^{\prime}-5^{\prime}}$

The fuel chemical exergy for a gaseous fuel is given by [17]:

$e x_{f}^{c h}=\left(1.033+0.0169 \frac{y}{x}-\frac{0.0698}{x}\right) L H V$

where $x$ and $y$ are the numbers of carbon and hydrogen atoms respectively.

For a liquid fuel, the fuel chemical exergy is calculated using [18]:

$e x_{f}^{c h}=\left(\begin{array}{l}1.0401+0.1728 \frac{h^{\prime}}{c^{\prime}}+0.0432 \frac{o^{\prime}}{c^{\prime}}+ \\ 0.2169 \frac{s^{\prime}}{c^{\prime}}\left(1-2.0628 \frac{n^{\prime}}{c^{\prime}}\right)\end{array}\right) L H V$

where $c^{\prime}, h^{\prime}, o^{\prime}, s^{\prime}$ and $n^{\prime}$ are the mass fraction of carbon atom $(\mathrm{C})$, hydrogen atom $(\mathrm{H})$, oxygen atom $(\mathrm{O})$, nitrogen atom $(\mathrm{N})$, and sulfur atom $(\mathrm{S})$ respectively.

\subsubsection{Catalytic Converter}

Within the catalytic converter, unburned carbon monoxide and hydrocarbons that may be contained in the exhaust gases leaving the engine are controlled. The exhaust gases gain some thermal energy by burning the aforementioned substances and $T_{7}$ can be determined by assuming adiabatic combustion, such that:

$$
\sum_{\text {Products }} n_{e}\left(\bar{h}_{f}^{0}+\Delta \bar{h}\right)_{e}=\sum_{\text {Re actants }} n_{i}\left(\bar{h}_{f}^{0}+\Delta \bar{h}\right)_{i}
$$

The exergy destruction within the catalytic converter is obtained by

$$
\dot{E} x_{D, c a t}=T_{0}\left(\dot{S}_{7}-\dot{S}_{6}+\dot{Q}_{\text {cat }} / T_{7}\right)
$$

where $\dot{S}_{7}-\dot{S}_{6}$ is the entropy generated in the catalytic converter, $\dot{Q}_{\text {cat }}$ is the heat acquired from burning unburned hydrocarbons and carbon monoxide.

\subsubsection{Turbine}

The turbine recovers part of the high enthalpy content in the exhaust gases considering a constant pressure turbocharging (area (7-7'-8'-8) in Figure 2) and uses it to produce the power required by the turbocharger compressor through expansion. The exit temperature of the turbine, $T_{8}$, is determined by knowing the turbine isentropic efficiency. Thus, the exergy destruction is expressed as

$$
\begin{aligned}
\dot{E} x_{D, t} & =\dot{E} x_{7}-\dot{E} x_{8}-\dot{W}_{t} \\
& =\dot{E} x_{7}-\dot{E} x_{8}-\left(\dot{m}_{a}+\dot{m}_{f}\right)\left(h_{7}-h_{8}\right)
\end{aligned}
$$

\section{Model Verification}

A FORTRAN program based on the aforesaid assumptions and equations has been developed to simulate the HCCI engine using alternative fuels from energy and exergy viewpoints. The developed thermodynamic model accuracy has been verified by comparing results with available data provided in the constructor catalog where the engine works in Dual Fuel mode LNG-diesel [19]. It was verified also for HCCI mode using hydrogen [20] and ethanol [1]. The same operating parameters used in the references cited have been introduced in the developed code to verify the accuracy of the model.

Table 3 resumes the comparison results between calculated values and those available in the constructor catalog [19]. The relative error between the two types of data is acceptable with a maximum of $4.1 \%$ for the $b s f c$ calculation

Table 3. Model verification results using the constructor catalog data [19]

\begin{tabular}{lccc}
\hline & Present Model & Catalog [19] & Error \\
\hline$T_{2}$ & 508.16 & 508.16 & $0 \%$ \\
$p_{2}$ & 4.08 & 4.08 & $0 \%$ \\
$T_{3}$ & 316.15 & 316.15 & $0 \%$ \\
$T_{8}$ & 628.1 & 603.15 & $1.252 \%$ \\
$W_{b}(\mathrm{~kW})$ & 17383.74 & 17550 & $0.947 \%$ \\
$\eta_{t h}(\%)$ & 49.21 & 48.13 & $2.240 \%$ \\
$b m e p(\mathrm{bar})$ & 18.9169 & 19.1 & $0.959 \%$ \\
$b s f c(\mathrm{~kJ} / \mathrm{kWh})$ & 7785.744 & 7479 & $4.101 \%$ \\
\hline
\end{tabular}


Figure 3.a shows a comparison between the calculated mean effective pressure and indicated power values with those measured by Antunes et al. [20] for engine inlet temperatures ranging from 85 to $110^{\circ} \mathrm{C}$. It can be observed that the calculation results using the established model are basically consistent with those of the literature. The same trend is observed between the two types of data. The mean deviation values are 2.36 and $2.59 \%$ for the indicated mean effective pressure and the indicated power, respectively. This deviation may be explained by the assumptions used which do not mirror the actual engine operation. Moreover, the heat transfer and friction correlations used need to be recalibrated based on experimental data which are not available for the case studied. Finally, some engine features such as fuel injection, valve lift, and pressure losses within intake and exhaust manifolds are not supported by the model proposed.

Similarly, the computed results in terms of the indicated engine efficiency have been compared to those presented in
Khaliq et al.[1] for several compressor pressure ratio values in Figure 3.b. A good agreement between the types of results is observed, which confirms the reliability of the model developed. Fortunately, the difference between the predictions of the two models is less than $4.3 \%$. This deviation can be explained by the assumptions used in the two models. In fact, Khaliq et al. [1] have adopted apolytropic assumption for compression and exhaust processes and they assigned a fixed exhaust gases composition under all operating conditions. However, in this work, as mentioned earlier, real compression and expansion processes based on isentropic efficiencies were adopted. Moreover, the composition of exhaust gases changed with respect to the operating conditions. Furthermore, the model takes account of heat transfer within the engine.

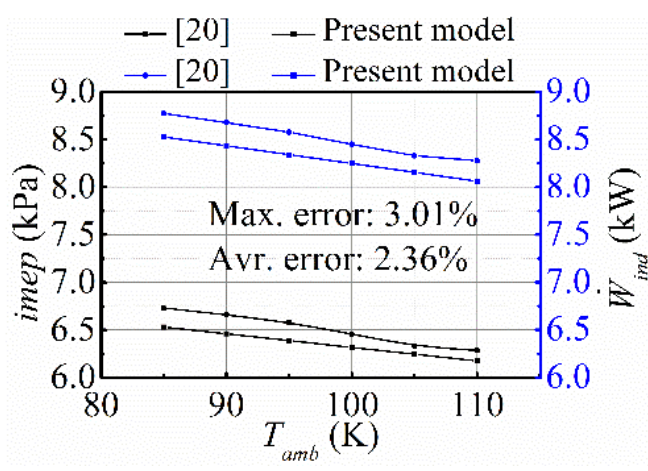

(a)

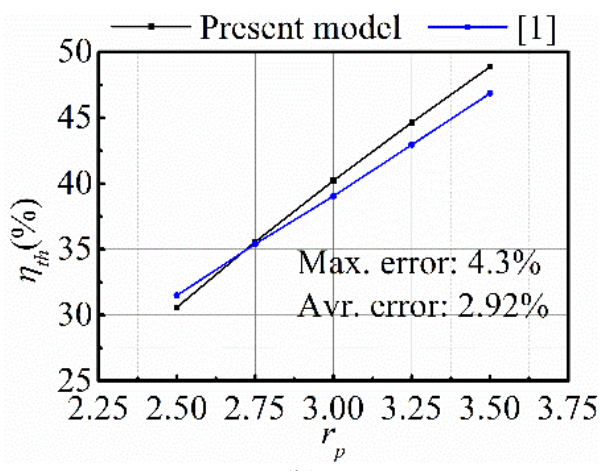

(b)

Figure 3. Verification cases results: (a). Comparisons with measurements of Antunes et al. [20]; (b). Comparisons with the model of Khaliq et al. [1]

\section{Results and Discussions}

The thermodynamic model described above has been used to develop a FORTRAN code, according to the flowchart given in Figure 4, to analyze the six alternative fuels under various operating parameters, namely engine compression ratio $\left(r_{c}\right)$, fuel-air equivalence ratio $(\phi)$, engine speed $(N)$, the engine inlet temperature $\left(T_{i n}\right)$ and turbo-compressor pressure ratio $\left(r_{p}\right)$. Performance parameters of the engine, namely the brake power output $\left(\dot{W}_{b}\right)$, the brake specific fuel consumption $(b s f c)$, the brake thermal efficiency $\left(\eta_{t h}\right)$, the exhaust gas temperature $\left(T_{\text {exh }}\right)$, and volumetric efficiency $\left(\eta_{v o l}\right)$ have been calculated as a function of selected engine parameters. For fixed engine inlet temperature, the volumetric efficiency depends only on the engine compression regardless of the fuel nature. Furthermore, individual and overall exergy destruction rates $\left(\dot{E} x_{D}\right)$ and the exergy efficiency $\left(\eta_{e x}\right)$ have been also evaluated as second-law parameters. As mentioned, the model considers real compression and expansion processes and heat transfer losses.

The compression ratio, the quotient of the combustion chamber's maximum volume to its minimum volume, is a key engine parameter that seriously affects the efficiency of the engine. It is also extremely crucial for the proper autoignition and functioning of a diesel engine. Figure 5 illustrates the variation of the brake specific fuel consumption, the brake power, the exhaust gases temperature, the brake efficiency, and the exergy efficiency with the compression ratio while maintaining the other parameters constants $\left(r_{p}=5.5, T_{i n}=365 \mathrm{~K}, \phi=0.4, N=500\right.$ rpm). The compression ratio was changed from 6 to 27 .

Theoretically, the increase of the compression ratio improves both the brake power output and brake efficiency.

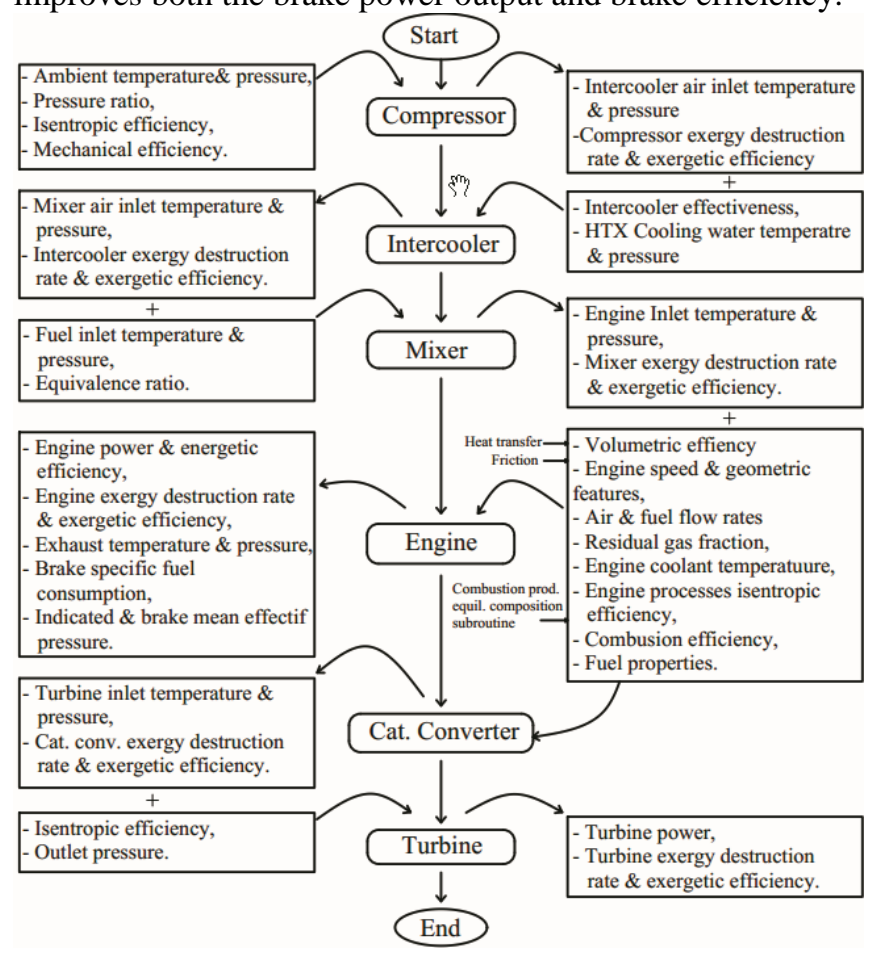

Figure 4. Thermodynamic modeling flowchart. 
However, for an actual cycle that includes real processes, the compression ratio affects differently the brake power output and brake efficiency. The brake power output and brake efficiency first increase and then start to decrease with increasing the compression ratio. The same behaviour has been obtained by Hassan et al. [21]. In fact, due to increased values of in-cylinder gases temperature and pressure, the brake power and brake efficiency are obviously increased as the compression ratio rises. However, due to the increase of the amount of heat transfer between combustion gases and the cylinder walls, they decrease for higher compression values. The amount of heat that could be converted to work output is undoubtedly reduced. The optimal compression ratio corresponding to maximum brake efficiency depends on the fuel nature. It is 16 for methanol, 18 for ethanol, 9 for LNG, 18 for LPG, 20 for biodiesel, and 15 for hydrogen. The exergy efficiency behaves similarly to the brake thermal efficiency but with different magnitudes as illustrated in Figure 5. For a fixed compression ratio, the engine uses a higher amount of fuel exergy compared to the fuel energy values, which results in lower exergetic efficiencies as compared to brake efficiencies. For compression ratios lower than 15, the highest engine performances (brake power output and brake and exergetic efficiencies) are associated with LNG fuel followed by methanol, biodiesel, LPG, ethanol, and hydrogen. For example, for $r_{c}=15$, the average drops in brake thermal efficiency compared to LNG are 18, 21.3, 33.6, 33.65, and $55.1 \%$ for methanol, biodiesel, LPG, ethanol, and hydrogen, respectively. The same trend is recorded for the exergetic efficiency. Methanol returns the highest brake specific fuel consumption, followed in order by ethanol, biodiesel, LPG, LNG, and hydrogen for compression ratios higher than 9. This is due to the combined influence of the stoichiometric air-fuel ratio and the lower heating value. The exhaust gases temperature decreases with increasing the compression ratio. It is found to be the highest for hydrogen and the lowest for LNG. This is attributed to the poor conversion of heat into work for the first and the better conversion of the second. The volumetric efficiency is insensitive to the fuel nature. According to equation (17), the volumetric efficiency is reduced as the compression ratio rises.
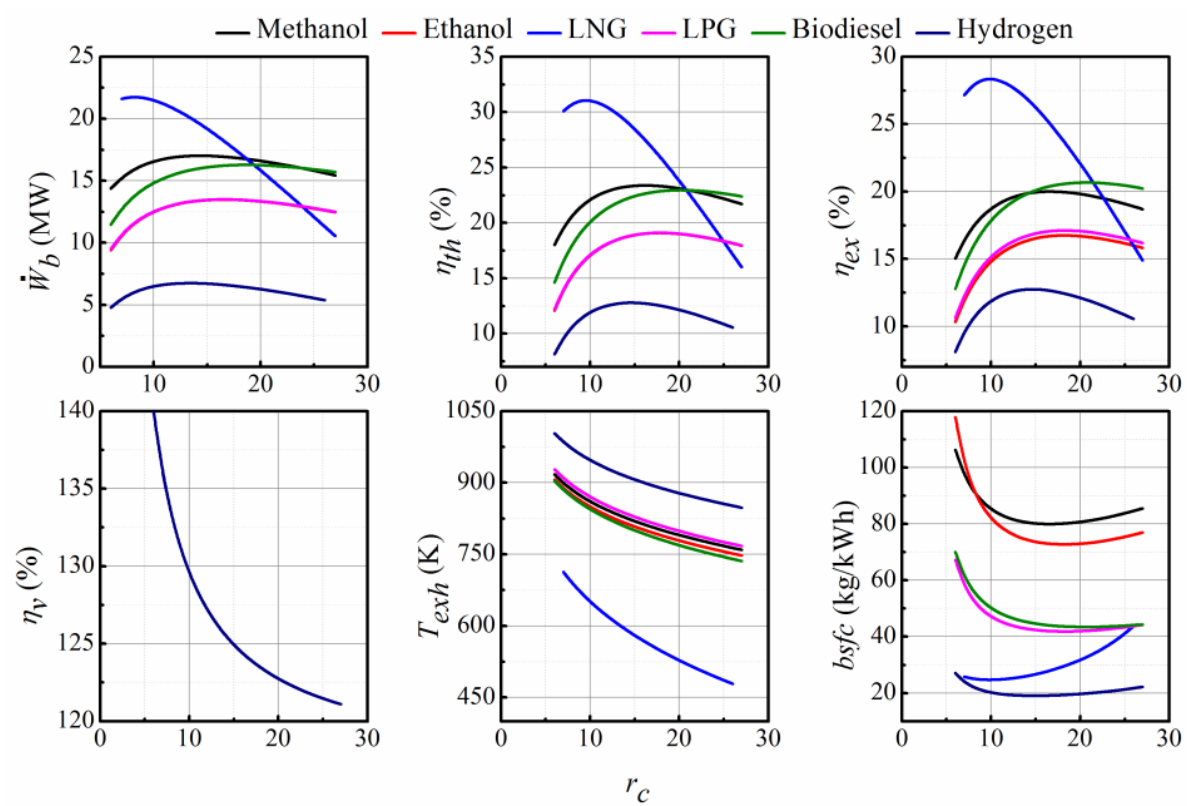

Figure 5. Engine performance variations for alternative fuels as function of the compression ratio $\left(r_{p}=5.5, T_{i n}=365 \mathrm{~K}, \phi\right.$ $=0.4, N=500 \mathrm{rpm}$ ).

The equivalence ratio is the primary parameter that determines the supplied energy. The engine performances are plotted versus the equivalence ratio in Figure 6 when the other parameters have been maintained constants $\left(r_{c}=\right.$ $\left.17, r_{p}=5.5, T_{i n}=365 \mathrm{~K}, N=500 \mathrm{rpm}\right)$. Results showed that, for all fuels, the brake specific fuel consumption is decreased with the increase of the equivalence ratio. However, the brake power output, brake and exergy efficiencies, and the exhaust gases temperature increase. This means that the conversion of the thermal energy released by the fuel at higher equivalence ratios is more efficient as observed by Hassan et al. [21]. The increase of equivalence ratio involves a higher heat release rate due to the larger amount of fuel that is auto-ignited at several locations. Overall, LNG fuelled HCCI engines perform better in terms of thermodynamic performance under the operating parameters considered in the current study. Higher values of in-cylinder temperature and air-fuel equivalence ratio of LNG give better brake efficiency compared to the other fuels. It is followed, in order, by methanol, biodiesel, LPG, ethanol, and hydrogen. It is also observed that the specific fuel consumption decreases with the increase of fuel-air equivalence ratio as expected from the definition of the. $b s f c$ is higher for methanol and ethanol fuels due to their inferior lower heating value compared to the other fuels. The engine exhaust gas temperature increases with increasing the equivalence ratio as illustrated in Figure6.This is can be attributed to high temperatures at the end of combustion which increases with increasing the mass of fuel burned. In addition, the exergetic efficiency increases as a consequence of the higher temperatures attained by the combustion for higher equivalence ratios. All exergy efficiency values are less than the corresponding brake efficiency values, due to the degradation of temperature as heat is transferred and stored. Since this degradation is reflected in the efficiencies based on exergy and not in those based on energy, exergy efficiencies are considered more meaningful. 


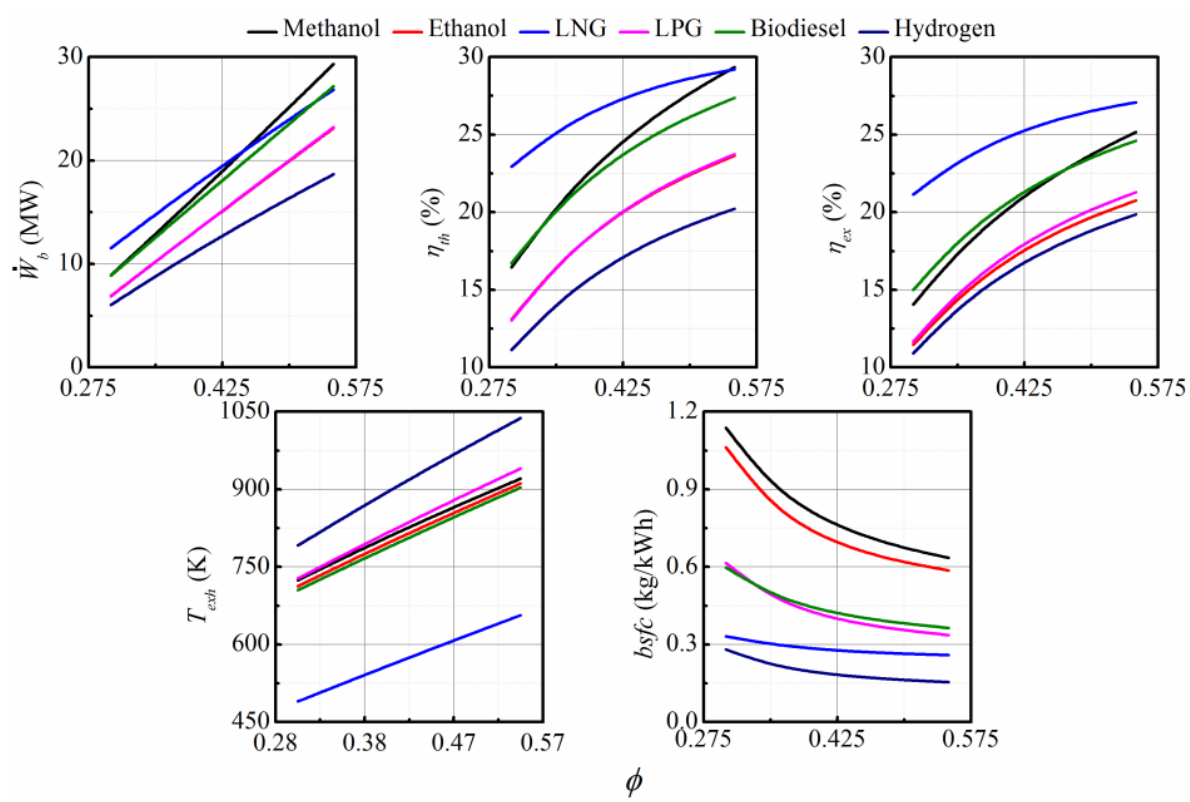

Figure 6. Engine performance variations for alternative fuels as function of the equivalence ratio $\left(r_{c}=17, r_{p}=5.5, T_{i n}=\right.$ $365 \mathrm{~K}, \mathrm{~N}=500 \mathrm{rpm})$.

Performance variations with respect to the engine speed for the assessed fuels are shown in Figure 7. Overall, and in consistence with Caton [22] and Kyritsis et al. [23], the engine brake power output, the brake efficiency, and the exergy efficiency are increased with the increment of engine speed for all fuels considered. A higher engine speed increases the charge-flow intensity and improves the mixing of fuel and air. Also, the heat loss to the cylinder

wall is reduced due to shorter combustion time which overpowers the increase of frictional and pumping losses. Furthermore, higher engine speed implies higher air and fuel mass rates resulting in higher maximal temperatures and pressures. The brake specific fuel consumption is reduced as the engine speed rises. Again, the order of the fuels in respect of their performances is respected for the same reasons as for the equivalence ratio effect.

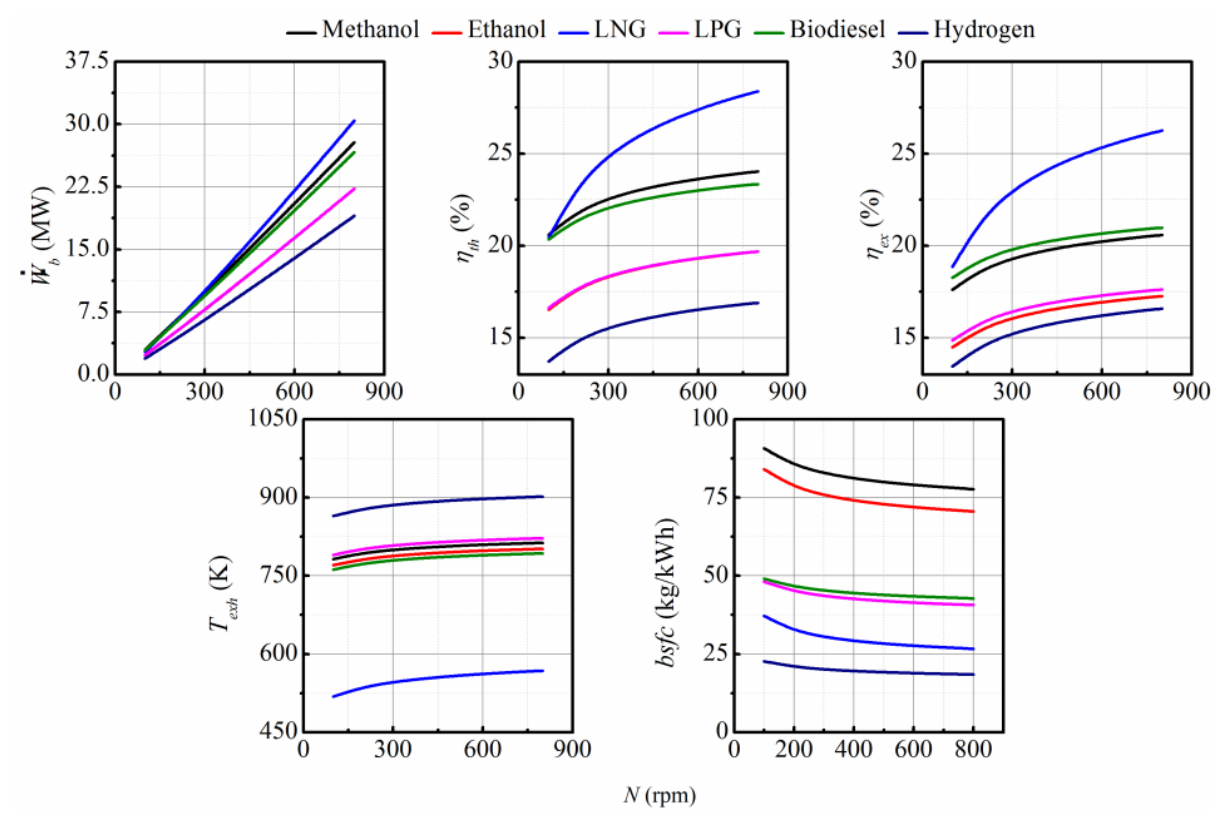

Figure 7. Engine performance variations for alternative fuels as function of the engine speed $\left(r_{c}=17, r_{p}=5.5\right.$, Tin $=365$ $K, \phi=0.4$ ).

The engine performances have been also obtained for engine inlet temperatures ranging from 345 to $385 \mathrm{~K}$ (Figure 8). Matching the trends obtained by Khaliq et al. [1], Hassan et al. [21] and Primus and Flynn [24], the increase of the engine inlet temperature results in a decrease of the brake power output, brake efficiency, and exergy efficiency, while the brake specific fuel consumption, the exhaust gases temperature and the volumetric efficiency are rate through the cylinder walls as a result of the increase of the temperature of combustion gases, as well as the deterioration of the charge density with an increase of inlet temperature for the same inlet pressure. For example, the brake power output is reduced roughly by $4.7 \%$ on average for every $10 \mathrm{~K}$ in the case of methanol, LNG, and biodiesel, while it is reduced by $6.5 \%$ for ethanol and LPG, and $8.5 \%$ for hydrogen. 


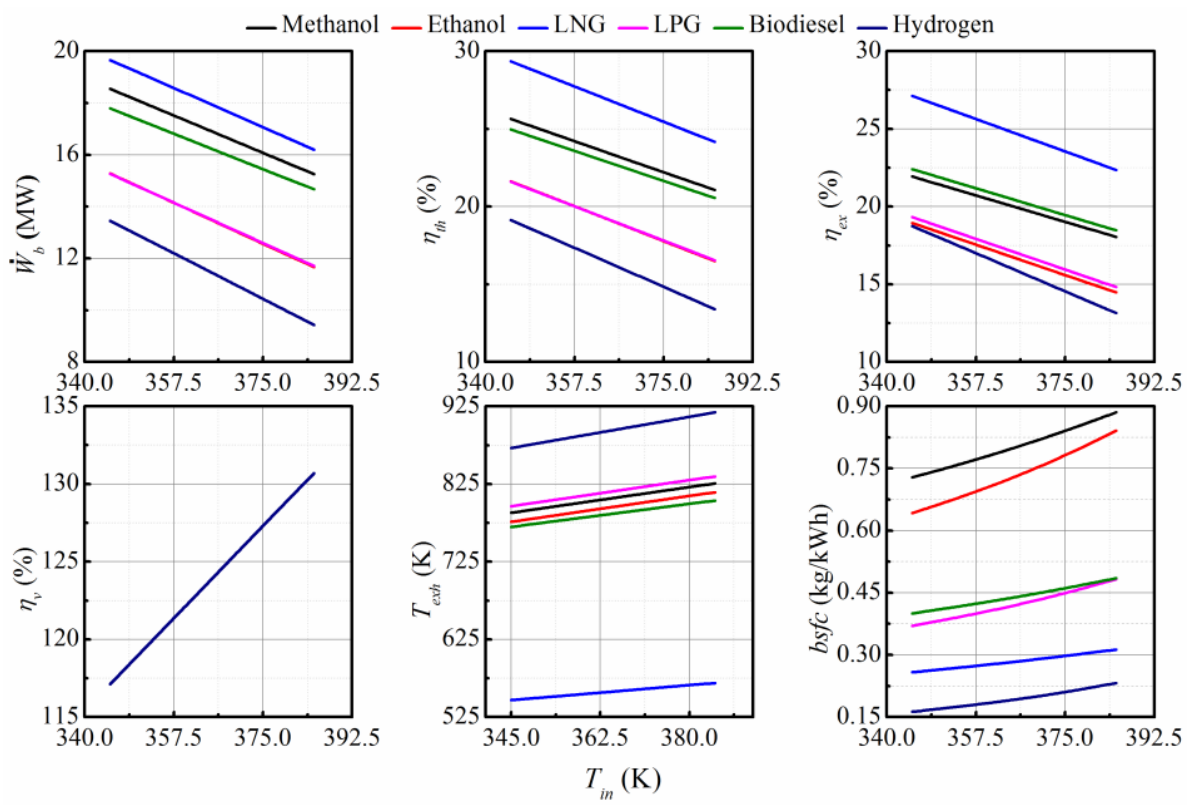

Figure 8. Engine performance variations for alternative fuels as function of the engine inlet temperature $\left(r_{c}=17, r_{p}=5.5\right.$, $N=500 \mathrm{rpm}, \phi=0.4$ ).

Turbocharger operating parameters play a crucial role in harvesting the exhaust gas energy efficiently. In fact, only a part of the exhaust energy is converted to mechanical work by the exhaust gas turbine. The converted proportion depends essentially on the turbine pressure ratio and on the efficiency of the turbocharger. In the following, the effect of the turbo-compressor pressure ratio $\left(r_{p}\right)$ on the engine performance is examined. In order to explain the effect of the turbo-compressor pressure ratio, the engine output parameters have been calculated for $r_{p}$ values ranging from 3.5 to 7.5. Results in terms of the engine brake thermal efficiency, the engine brake power, the exhaust gases temperature, and the engine exergy efficiency for the six fuels tested are presented in Figure 9. They are obtained for an engine compression ratio of 17 , an engine inlet temperature of $365 \mathrm{~K}$, an air-fuel equivalence ratio of 0.4 and an engine speed of $500 \mathrm{rpm}$. At first glance, all fuels behave similarly, increasing the turbo-compressor pressure ratio increases the thermal and exergy efficiencies, the brake fuel specific consumption, the brake power, and the exhaust gases temperature. Indeed, increasing the amount of air with higher pressures in the engine cylinder increases the fuel quantity and by the way, it increases the power output. For example, for LNG fuel, it is observed that when the compressor ratio is elevated from 3.5 to 7.5 , the brake power is increased by $138 \%$, while the thermal efficiency is enhanced by $11 \%$. Overall, LNG performs the best, followed, in order, by methanol, biodiesel, LPG, ethanol, and hydrogen.

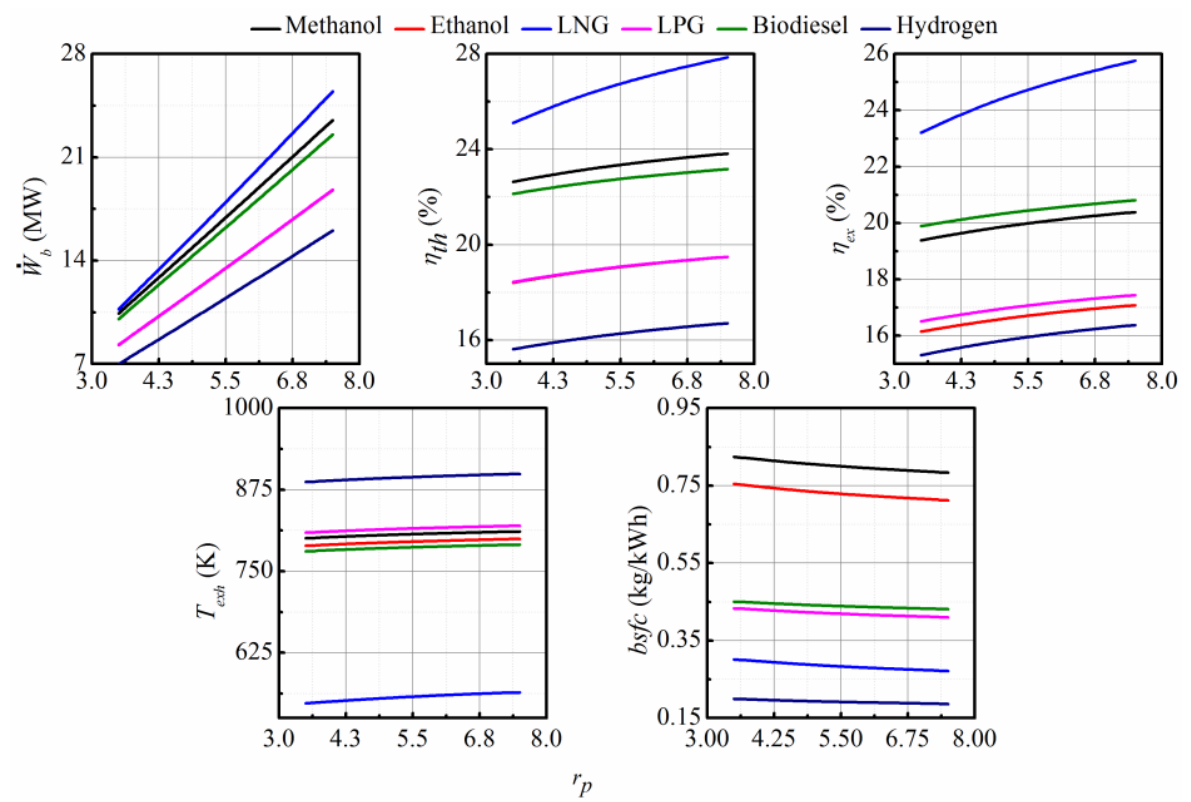

Figure 9. Engine performance variations for alternative fuels as function of the turbo-compressor pressure ratio $\left(r_{c}=17\right.$, $\operatorname{Tin}=365 \mathrm{~K}, \mathrm{~N}=500 \mathrm{rpm}, \phi=0.4)$. 
From a second-law point of view, it is important to quantify the exergy destructions in each component of the system in order to assess its overall performance. Exergy destructions in each component of the system have been evaluated and related to the total exergy destruction in the system using

$$
\% \Delta \dot{E} x_{k}=\frac{\dot{E} x_{D}}{\dot{E} x_{D}} \times 100
$$

A mapping of exergy destruction rates in the whole system is performed for fixed operating conditions $\left(r_{c}=17, r_{p}=5.5\right.$, $\left.T_{\text {in }}=365 \mathrm{~K}, \phi=0.4, N=500 \mathrm{rpm}\right)$. Thus, the percent of exergy destruction rates within all the components of the system are presented in Figure 10 for the six fuels tested. The comparison between exergy destruction rates of the individual component shows that the HCCI engine is the major source of the irreversibility of the system. Depending on the fuel, it counts alone for 79.9 to $87.8 \%$ of the total exergy destruction rate in the system. The remaining components (turbo-compressor, intercooler, mixer, catalytic converter, and turbine) are responsible of only 12.2 to $20.1 \%$ of the total exergy destruction rate of the system. For example, for LNG fuel, the exergy destruction rate of the compressor, the turbine, the heat exchanger, the mixer and the catalytic converter are only $2.2,2.6,3.1,2.4$, and $10.9 \%$, respectively. The exergy destructions in the system are mainly due to the irreversible nature of the combustion process, heat transfer through a finite temperature difference, friction, and mixing process. The exergy destruction in the HCCI engine is mainly due to the combustion reaction and to the large temperature difference during heat transfer between the combustion gases and the surrounding. The frictional effects, pressure drops, and heat losses to the environment are the main causes of the exergy destruction in the turbine. The exergy destruction within the compressor originates from the fluid flow losses due to fluid shear and throttling. The exergy destruction in the intercooler is due to the finite temperature difference between the cooling water and the intake air, which interchange heat. It can be concluded that the HCCI engine is the key component for any suggested improvements, due to its large exergy destruction amount.

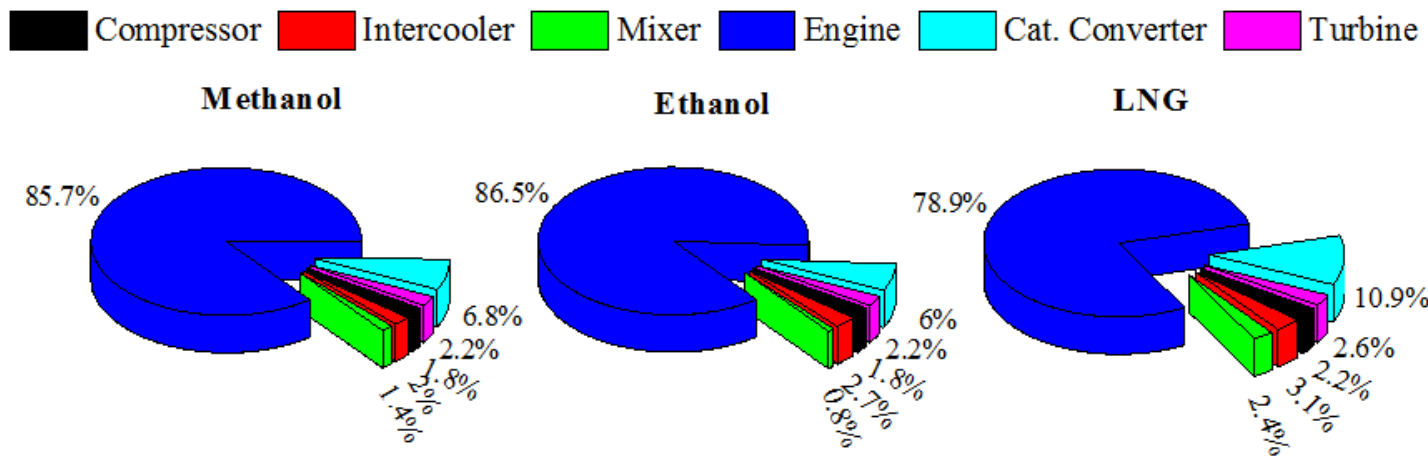

LPG

Biodiesel

Hyd rogen
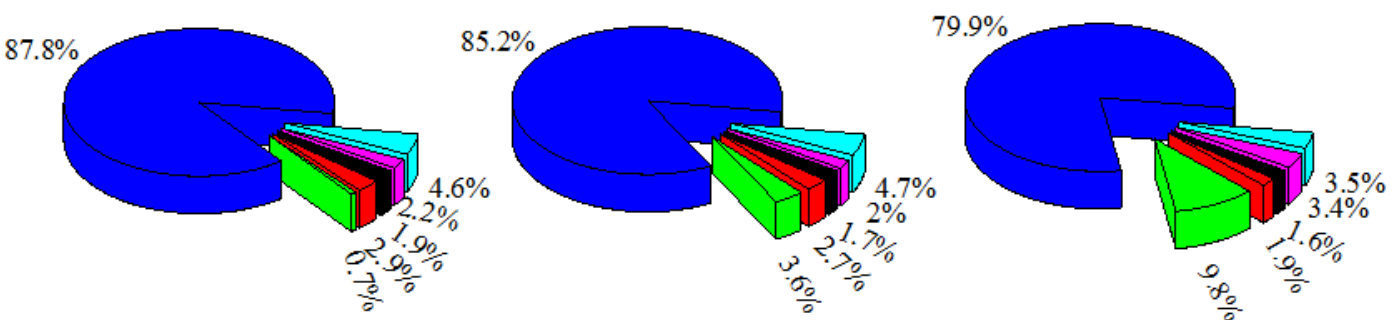

Figure 10. Exergy destruction mapping within the system $\left(r_{c}=17, r_{p}=5.5, T_{i n}=365 \mathrm{~K}, \phi=0.4, \mathrm{~N}=500 \mathrm{rpm}\right)$.

The above results show that the HCCI engine irreversibilities are dominant. Hence, Figure 11 is dedicated to a detailed analysis of the exergy rate during the different processes occurring in the HCCI engine. From Figure 10, it can be observed that combustion is the key process for improvements due to its large exergy destruction amount. The latter represents 70.43 to $90.71 \%$ of the total exergy losses within the HCCI engine. The large exergy destruction rate during the combustion process is associated with large temperature variation. The compression stroke produces less irreversibility compared to the combustion process $(3.1-22.21 \%)$. Expansion and exhaust strokes generate minor irreversibilities due to lower temperatures and pressures of the expanding working fluid. 

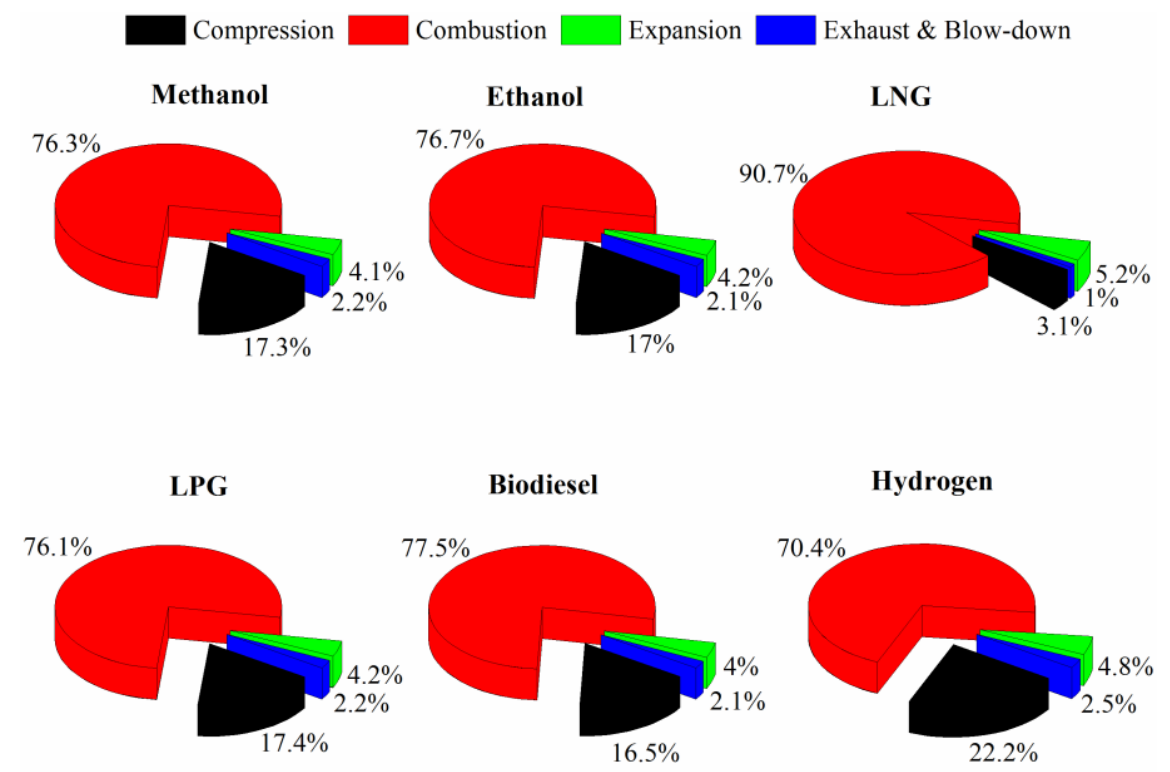

Figure 11. Exergy destruction mapping for the HCCI engine processes $\left(r_{c}=17, r_{p}=5.5, T_{i n}=365 \mathrm{~K}, \phi=0.4, N=500\right.$ rpm).

\section{Conclusions}

In this paper, the performance of prospective alternative fuels, namely natural gas, LPG, biodiesel, ethanol, methanol, and hydrogen in an HCCI engine have been analyzed. The engine-output parameters considered in the present study include the brake specific fuel consumption, the brake thermal efficiency, the brake power, the exergy efficiency, the exhaust gases temperature, and the volumetric efficiency. Results showed that the assessed fuels behave differently in an HCCI engine. Further conclusions are raised below:

- The engine operating parameters considered in the present study $\left(r_{c}, r_{p}, T_{i n}, \quad N\right.$ and $\left.\phi\right)$ affect considerably the engine performance. Generally, the engine performances are improved with different levels by rising the engine operating parameters cited above, due mainly to a better combustion process.

- The fuel nature has a significant impact on the thermal performance of an HCCI engine. The highest engine performance values are obtained using LNG as fuel, followed, in order, by methanol, biodiesel, LPG, ethanol, and hydrogen. Although hydrogen is associated with a higher energy value, it produces lower performance compared to the other fuels assessed.

- Qualitatively, the exergetic efficiency behaves similarly to the brake efficiency but exhibits much lower magnitudes.

- The exhaust gas temperature is mainly affected by the specific fuel consumption. The highest value of exhaust gas temperature $\left(621.13^{\circ} \mathrm{C}\right)$ is obtained with hydrogen and the lowest $\left(284.58^{\circ} \mathrm{C}\right)$ is attained in the case of hydrogen as fuel at standard conditions.

- The exergy analysis led to several notable findings. Most of the exergy destruction rates (78.9-87.8\%) occur in the HCCI engine. The order of exergy destruction rates within the other components differs from fuel to other. As a result, a large potential can be achieved to improve the system efficiency by reducing HCCI engine exergy losses. This can be done by improving the combustion processes.

\section{Acknowledgements}

This study was supported by the Algerian Ministry of Higher Education and Scientific Research (MESRS) and the Directorate-General of Scientific Research and Technological Development (DGRSDT).

\section{Nomenclature}

bsfc Brake specific fuel consumption $(\mathrm{g} / \mathrm{kWh})$

bmep Brake mean effective pressure $(\mathrm{kPa})$

$\dot{E x} \quad$ Exergy rate $(\mathrm{kW})$

ex $\quad$ Specific exergy $(\mathrm{kJ} / \mathrm{kg})$

$h \quad$ Specific enthalpy

imep Indicated mean effective pressure $(\mathrm{kPa})$

LHV Lower heating value $(\mathrm{kJ} / \mathrm{kg})$

$\dot{m} \quad$ Mass flow rate $(\mathrm{kg} / \mathrm{s})$

W Power $(k W)$

$\dot{O} \quad$ Heat transfer rate $(k W)$

s Specific Entropy $(\mathrm{kJ} / \mathrm{kg} . \mathrm{K})$

\section{Greek Symbols}

$\varepsilon \quad$ Intercooler effectiveness

$\phi \quad$ Fuel-air equivalence ratio

$\eta \quad$ Efficiency

\section{Subscripts}

$\begin{array}{ll}b & \text { Brake } \\ \text { comb, comp } & \text { Combustion, Compressor } \\ \text { gen } & \text { Generated } \\ i & \text { Indicated } \\ \text { int } & \text { Intercooler } \\ \text { is } & \text { Isentropic } \\ \text { mix } & \text { Mixer } \\ \text { out } & \text { Output } \\ t & \text { Turbine } \\ \text { th } & \text { Thermal } \\ \text { vol } & \text { Volumetric }\end{array}$




\section{References:}

[1] Khaliq, S.K. Trivedi, I. Dincer, "Investigation of a Wet Ethanol Operated HCCI Engine Based on First and Second Law Analyses,"Appl. Therm. Eng., 31, pp. 621-1629, 2011.

[2] S.K. Trivedi, A. Haleem, "Thermodynamic Analysis and Utilization of Wet Ethanol in Homogeneous Charge Compression Ignition Engine,"Int. J. Sust. Energy, 35, pp. 33-46, 2013.

[3] G.R. Fatehi, S. Khalilarya, R. Ebrahimi, "Energy and Exergy Analyses of Homogeneous Charge Compression Ignition (HCCI) Engine,"Thermal Sci., 17, pp. 107-17, 2013.

[4] S. Jafarmadar, N. Javani, "Exergy Analysis of Natural Gas/DME Combustion in Homogeneous Charge Compression Ignition Engines (HCCI) Using ZeroDimensional Model with Detailed Chemical Kinetics Mechanism,'Int. J. Exergy, 15, pp. 363-81, 2014.

[5] M. Djermouni, A. Ouadha, "Thermodynamic Analysis of an HCCI Engine Based System Running on Natural Gas,"Energy Convers. Manag., 88, pp. 723-731,2014.

[6] A. Khaliq, "Energy and Exergy Analyses of a Hydrogen Fuelled HCCI Combustion Engine Combined with Organic Rankine Cycle,"Int. J. Exergy, 17, pp. 240-265, 2015.

[7] S. Mamalis, D.N.Assanis, "Second-law Analysis of Boosted HCCI Engines: Modeling Study,"J. Energy Eng., 141:C4014014.

[8] Y. Li, M. Jia, Y. Chang, L.K. Kokjohn, R.D. Reitz, "Thermodynamic Energy and Exergy Analysis of Three Different Engine Combustion Regimes,"Appl. Energy, 180, pp. 849-858,2016.

[9] M. Djermouni, A. Ouadha, "Comparative Assessment of LNG and LPG in HCCI Engines,'Energy Procedia, 139, pp. 254-259,2017.

[10] A. Khaliq, S. Islam, I. Dincer, "Energy and Exergy Analyses of a HCCI Engine-based System Running on Hydrogen Enriched Wet-Ethanol Fuel,'Int. J. Exergy, 28, pp. $72-95,2019$.

[11] M.M. Namar, O. Jahanian, "Energy and Exergy Analysis of a Hydrogen-Fueled HCCI Engine,"J. Therm. Anal. Calorim., 137, pp. 2005-2015, 2019.

[12] S. Aceves, D. Flowers, "Engine Shows Diesel Efficiency without the Emissions,"Lawrence Livermore National Laboratory:Livermore, CA, USA, 2004.

[13] H. Hiereth, P. Prenninger, Charging the Internal Combustion Engine, Vienna, Austria: SpringerVerlag, 2003.

[14] J.B. Heywood, Internal Combustion Engine Fundamentals, New York: McGraw-Hill, Inc., 1988.

[15] H.S. Soyhan, H. Yasar, H. Walmsley, B. Head, Kalghatgi, G.T., and Sorusbay, C., Evaluation of Heat "Transfer Correlations for HCCI Engine Modeling,"Appl. Thermal Eng., 29, pp. 541-549, 2009.

[16] R. Stone, Introduction to Internal Combustion Engines, $3^{r d} E d$., MacMillan Press Ltd, 1999.

[17] A.Bejan, Advanced Engineering Thermodynamics, $2^{\text {nd }}$ Ed. New York: John Wiley \& Sons, Inc., 1997.

[18] T.J.Kotas, The Exergy Method of Thermal Plant Analysis, Great Britain: Anchor Brendon Ltd., 1995.

[19] 51/60DF Project guide-Marine Four-Stroke dual-fuel engines compliant with IMO Tier II, Augsburg: MAN
Diesel \& Turbo SE, 2013.

[20] J.M.G. Antunes, R. Mikalsen, A.P. Roskilly, “An Investigation of Hydrogen-Fuelled HCCI Engine Performance and Operation,'Int. J. Hydrogen Energy, 33, pp. 5823-5828, 2008.

[21] M.M. Hassan, M.M. Rahman, K. Kadirgama, D. Rasamy, “ Numerical Study of engine parameters on combustion and performance characteristics in an nheptane fueled HCCI engine,"Appl. Therm. Eng., 128, pp. 1464-1475, 2018.

[22] J.A. Caton, An Introduction to Thermodynamic Cycle Simulations for Internal Combustion Engines, Chechister: John \& Wiley \& Sons, Ltd., 2016.

[23] D.C. Kyritsis, C.D. Rakopoulos, "Parametric Study of the Availability Balance in an Internal Combustion Engine Cylinder," SAE paper, 2001-01-1263, 2001, 2001.

[24] R.J. Primus, P.F. Flynn, "Diagnosing the Real Performance Impact of Diesel Engine Design Parameter Variation (A Primer in the Use of Second Law Analysis)," Cummins Engine Co., Inc., 1984. 